\title{
Efeito da adição de trolox e pentoxifilina na motilidade, integridade do acrossoma e do DNA de espermatozoides equinos após descongelação
}

\author{
[Effect of trolox and pentoxifylline on motility and integrity of, acrossome and DNA of \\ equine spermatozoa after thawing] \\ K.M.G. Silva ${ }^{1}$, T.A.P. Moraes $^{1}$, E.C.B. Silva ${ }^{1}$, S.C. Gamboa ${ }^{2}$, M.M.P. Guerra ${ }^{1}$ \\ ${ }^{1}$ Departamento de Medicina Veterinária - UFRPE - Recife, PE \\ ${ }^{2}$ Escola Superior Agrária - Instituto Politécnico de Coimbra - Bencanta - Coimbra, Portugal
}

\begin{abstract}
RESUMO
Três garanhões foram utilizados para estudar o efeito da adição de trolox e pentoxifilina na motilidade, integridade do acrossoma e DNA de espermatozoides pós-descongelação. Para congelação, utilizou-se Tris-gema com glicerol (5\%) em máquina de congelação de sêmen. As amostras foram descongeladas a $37^{\circ} \mathrm{C}$ durante 30 segundos e tratadas com: $\mathrm{T} 1=150 \mu \mathrm{L}$ de sêmen $+150 \mu \mathrm{L}$ de Tris; $\mathrm{T} 2=150 \mu \mathrm{L}$ de sêmen + $150 \mu \mathrm{L}$ de Tris $+120 \mu \mathrm{M} / \mathrm{mL}$ de trolox; $\mathrm{T} 3=150 \mu \mathrm{L}$ de sêmen $+150 \mu \mathrm{L}$ de Tris $+3,5 \mathrm{mM}$ de pentoxifilina e $\mathrm{T} 4=150 \mu \mathrm{L}$ de sêmen $+150 \mu \mathrm{L}$ de Tris $+3,5 \mathrm{mM}$ de pentoxifilina $+120 \mu \mathrm{M} / \mathrm{mL}$ de trolox. Após 0,60 e 120 minutos de incubação $\left(37^{\circ} \mathrm{C}\right)$, as amostras foram analisadas quanto à motilidade, vigor, integridade de acrossoma e DNA. Não houve diferença $(\mathrm{P}>0,05)$ entre tratamentos após 0 e 60 minutos de incubação em todos os parâmetros estudados. Após 120 minutos de incubação, verificou-se maior porcentual $(\mathrm{P}<0,05)$ de células com motilidade total e progressiva nas amostras do T2. Conclui-se que a adição de trolox após descongelação do sêmen equino preserva a motilidade total e progressiva dos espermatozoides submetidos à incubação a $37^{\circ} \mathrm{C}$ durante 120 minutos.
\end{abstract}

Palavras-chave: equino, sêmen, incubação, antioxidante

\begin{abstract}
Three stallions were used to study the effect of trolox and pentoxifylline addition on the motility and integrity of acrossome and DNA equine spermatozoa after thawing. Tris-egg-yolg diluent with glycerol $(5 \%)$ were used to freeze the semen samples in a freezing machine. The samples were thawed at $37^{\circ} \mathrm{C}$ during 30 seconds and treated with: $T 1=150 \mu \mathrm{L}$ of semen $+150 \mu \mathrm{L}$ of Tris; $T 2=150 \mu \mathrm{L}$ of semen $+150 \mu \mathrm{L}$ of Tris $+150 \mathrm{mM} / \mathrm{mL}$ of trolox; $T 3=150 \mu \mathrm{L}$ of semen $+150 \mu \mathrm{L}$ Tris $+3.5 \mathrm{mM}$ of pentoxifylline; and T4= $150 \mu \mathrm{L}$ of semen $+150 \mu \mathrm{L}$ of Tris $+3.5 \mathrm{mM}$ of pentoxifylline $+150 \mathrm{mM}$ of trolox. After 0, 60, and 120 minutes of incubation $\left(37^{\circ} \mathrm{C}\right)$, the samples were analyzed to motility, vigor, and integrity of acrossome and DNA. There was no difference $(P>0.05)$ among treatments considering 0 and 60 minutes of incubation in all studied parameters. After 120 minutes of incubation, it was observed higher percentage $(P<0.05)$ of cells with total and progressive motility in the samples of T2. It can be concluded that the trolox addition after thawing of equine semen preserved total and progressive motility of the sperm incubated at $37^{\circ} \mathrm{C}$ during 120 minutes.
\end{abstract}

Keywords: equine, semen, incubation, antioxidant

\section{INTRODUÇÃO}

$\mathrm{Na}$ maioria dos garanhões, as características espermáticas pós-congelação apresentam características inadequadas, resultando em índices baixos de fertilidade, como consequência das crioinjúrias espermáticas ocorridas durante $\mathrm{o}$ processo de congelação/descongelação. Por isso, várias pesquisas têm sido realizadas com $\mathrm{o}$ intuito de melhorar a qualidade espermática

Recebido em 26 de maio de 2008

Aceito em 23 de dezembro de 2008

E-mail: karenmascaro1@hotmail.com 
(Dell'Áqua Júnior e Papa, 2001; Snoeck et al., 2007) visando aumentar as taxas de prenhez nessa espécie.

O papel das espécies reativas ao oxigênio (ROS) tem sido enfatizado na fisiopatologia da reprodução e, apesar de estar envolvido no controle fisiológico de algumas funções espermáticas, como capacitação e reação do acrossoma, a sua produção excessiva é prejudicial em virtude de reduzir a motilidade espermática, a capacidade de fusão dos gametas e a fertilidade (Guerra et al., 2004). Sabe-se que muitos procedimentos utilizados em laboratório podem interferir na produção de ROS espermáticos, tendo sido demonstrado aumento de sua concentração em amostras de sêmen dos animais domésticos submetidas à centrifugação (Twigg et al., 1998) e congelação (Wang et al., 1997; Ball et al., 2001; Chatterjee e Gagnon, 2001).

Durante a congelação, a produção de ROS pode induzir mudanças na estrutura e na função espermática (Ball et al., 2001), além de alterar o sistema de defesa antioxidante (Bilodeau et al., 2000). Por isso, Gadea et al. (2005), visando aumentar a viabilidade e a subsequente capacidade fertilizante de espermatozoides suínos, sugeriram a adição de antioxidante ao meio diluidor após a descongelação, em virtude de reduzir a produção de ROS e aumentar a habilidade de penetração no oócito.

Os antioxidantes são inibidores de radicais livres que suprimem a formação de ROS e/ou suas ações. Estudos têm mostrado que a vitamina $\mathrm{E}$ ( $\alpha$-tocoferol) é capaz de interagir diretamente com radicais oxidantes (Jones et al., 1995) interrompendo a reação em cadeia da peroxidação lipídica em biomembranas e lipoproteínas (Dieber-Rotheneder et al., 1991) e protegendo as células de estresse oxidativo (Kagan et al., 1992) e de danos das membranas plasmática e acrossomal, bem como do DNA (Sikka, 2004). O trolox (6-hydroxy-2,5,7,8tetramethylchroman-2-carboxylic acid) é um análogodo $\alpha$-tocoferol hidrossolúvel que, devido à sua solubilidade em água, apresenta potente propriedade antioxidante (Wu et al., 1991).

A pentoxifilina está sendo utilizada nos casos de infertilidade causada por fator masculino na espécie humana, levando em consideração a sua capacidade de preservar a capacidade fertilizante dos espermatozoides (Goulart et al., 2004). Segundo Yovich (1993), esse inibidor da fosfodiesterase auxilia na fertilização do ovócito durante os procedimentos de fertilização in vitro, promovendo aumento de sua motilidade. No sêmen equino, a pentoxifilina aumentou a motilidade progressiva de espermatozoides descongelados após incubação nos momentos 0 e 120 minutos (Marques et al., 2002).

Considerando que o uso da pentoxifilina associada ao trolox aumenta a viabilidade de espermatozoides descongelados, este estudo teve o objetivo de avaliar o efeito da adição de trolox e de pentoxifilina na motilidade, integridade do acrossoma e do DNA de espermatozoides de equinos após a descongelação.

\section{MATERIAL E MÉTODOS}

Amostras de sêmen foram obtidas de três garanhões da raça Mangalarga Marchador, com idades entre quatro e oito anos, os quais permaneceram estabulados durante 0 experimento, junho e julho, e foram alimentados com ração balanceada e feno. Os animais foram avaliados por meio de exame andrológico, sendo aprovados para congelação apenas os ejaculados com valores mínimos de $60 \%$ de motilidade total e 3 de vigor espermático.

A cada três dias, foram colhidas amostras de sêmen, totalizando três ejaculados de cada reprodutor, mediante uso de vagina artificial, com auxílio de uma égua em cio. Imediatamente após a colheita, procedeu-se à filtragem das amostras de sêmen com gaze, visando remover o gel e as partículas grandes de debris celulares. As amostras sem gel foram colocadas em banhomaria a $35^{\circ} \mathrm{C}$ durante os procedimentos de diluição e análise espermática: motilidade total e progressiva, e concentração espermática que foram avaliadas segundo o Manual para exame andrológico e avaliação de sêmen animal do CBRA (Manual ..., 1998). Em seguida, o sêmen diluído (1:1, sêmen:diluidor; Kenney, 1975) foi transportado à temperatura ambiente ao laboratório para congelação.

Foram preparadas as amostras de sêmen in natura para avaliação de: a) integridade do acrossoma, em que $10 \mu \mathrm{L}$ do sêmen diluído $1: 1$ (sêmen:diluidor; Kenney, 1975) foi utilizado 
para confecção de esfregaços, os quais foram armazenados a $4^{\circ} \mathrm{C}$, protegidos da luz e analisados no prazo de duas semanas utilizandose a técnica de coloração FITC-conjugada ao Pisun sativun aglutinina ${ }^{1}$ (FITC-PNA; Roth et al., 1998); b) integridade do DNA, em que a alíquota de $10 \mu \mathrm{L}$ de sêmen foi diluída em $990 \mu \mathrm{L}$ de solução de TNE contendo $0,15 \mathrm{M} \mathrm{NaCl}$; $0,01 \mathrm{M}$ TRIS.HCl; $1 \mathrm{mM}$ EDTA. $\mathrm{Na}_{2} \cdot 2 \mathrm{H}_{2} \mathrm{O}$ em $100 \mathrm{~mL}$, cujo $\mathrm{pH}$ foi em torno de 7,4 ; colocadas em tubos de microcentrífuga $(1,5 \mathrm{~mL})$ e incubadas a $-20^{\circ} \mathrm{C}$, para posterior análise, de acordo com a técnica de laranja de acridina $^{2}$ (Evenson et al., 1999).

Antes do procedimento de congelação, as amostras de sêmen foram centrifugadas (600 x g, durante 10 minutos) para retirada do plasma seminal e os péletes ressuspensos em diluidor de congelação $\mathrm{FR}^{3}$ (Tris-gema com $5 \%$ de glicerol), na concentração de $100 \times 10^{6}$ espermatozoides $/ \mathrm{mL}$. A seguir, as amostras foram envasadas em palhetas de $0,25 \mathrm{~mL}$ e transferidas imediatamente para a máquina de congelação de sêmen ${ }^{4}$, onde foram submetidas ao processo de refrigeração iniciando à temperatura ambiente até atingir $5^{\circ} \mathrm{C}$, a uma taxa de $0,25^{\circ} \mathrm{C} / \mathrm{min}$. A partir daí, foram realizadas duas curvas negativas, a primeira de $-15^{\circ} \mathrm{C} / \mathrm{min}$ até atingir $-5^{\circ} \mathrm{C}$, e a segunda a $-10^{\circ} \mathrm{C} / \mathrm{min}$ até atingir $-120^{\circ} \mathrm{C}$. Após o processo de congelação, as palhetas foram armazenadas em botijão criobiológico à temperatura de $-196^{\circ} \mathrm{C}$.

Para descongelação, duas palhetas de sêmen de cada reprodutor foram colocadas a $37^{\circ} \mathrm{C}$, durante 30 segundos. Em seguida, as amostras foram diluídas em solução Tris (1:1; v:v) acrescida de trolox e pentoxifilina de acordo com os seguintes tratamentos $(\mathrm{T}): \mathrm{T} 1=150 \mu \mathrm{L}$ de sêmen $+150 \mu \mathrm{L}$ de Tris (controle); T2 $=150 \mu \mathrm{L}$ de sêmen + $150 \mu \mathrm{L}$ de Tris $+120 \mu \mathrm{M} / \mathrm{mL}$ de trolox ${ }^{1}$; T3= $150 \mu \mathrm{L}$ de sêmen $+150 \mu \mathrm{L}$ de Tris $+3,5 \mathrm{mM}$ de pentoxifilina $^{5}$ e T4 $=150 \mu \mathrm{L}$ de sêmen $+150 \mu \mathrm{L}$ de Tris $+3,5 \mathrm{mM}$ de pentoxifilina $+120 \mu \mathrm{M} / \mathrm{mL}$ de trolox. As amostras foram analisadas quanto à motilidade total e progressiva, vigor e

${ }^{1}$ Sigma - Saint Louis, EUA.

${ }^{2}$ Molecular Probes Inc. - Oregon, EUA.

${ }^{3}$ Nutricell - Porto Alegre, Brasil.

${ }^{4}$ Modelo Tetakon ${ }^{\circledR}$-TK 3000, Tecnol. Congel. Ltda -

Uberaba, Brasil.

${ }^{6}$ A Fórmula - Salvador, Brasil. integridade de acrossoma e DNA, nos momentos 0,60 e 120 minutos de incubação a $37^{\circ} \mathrm{C}$ em banho-maria. As concentrações de pentoxifilina e trolox foram baseadas em estudos preliminares desenvolvidos por Silva et al. (2006).

As características espermáticas - motilidades total e progressiva, vigor, integridade acrossomal e integridade de DNA - de cada reprodutor foram avaliadas antes e após a congelação, bem como após diluição e incubação de 60 e 120 minutos. Aplicou-se análise de variância considerando os fatores tratamento e tempo de incubação das amostras e sua interação. A significância estatística foi estabelecida para 0,05 de probabilidade.

\section{RESULTADOS E DISCUSSÃO}

As análises das amostras de sêmen realizadas imediatamente após a descongelação e diluição, e aos 60 minutos de incubação, não evidenciaram diferenças $(\mathrm{P}>0,05)$ entre os tratamentos para motilidade total e progressiva, vigor, integridade de acrossoma e DNA (Fig. 1I, II, III e 2I, II). Entretanto, aos 120 minutos de incubação, verificou-se diferença entre tratamentos $(\mathrm{P}<0,05)$ na motilidade total e na motilidade progressiva, sendo os valores de T2 e T4 mais elevados do que os dos T1 e T3 (Fig. 1I e II).

Segundo Marques et al. (2002), a adição de $3,5 \mathrm{mM}$ de pentoxifilina em diluidor TALP, com ou sem ácido ascórbico, após descongelação do sêmen equino criopreservado em diluidor à base de gema de ovo $(20,0 \%)$ e Orvus-Es Past, agente emulsificante que aumenta a proteção dos fosfolipídios, preservou a motilidade progressiva e o vigor espermático do momento 0 até 120 minutos de incubação. Isto não foi observado nesse experimento, em que a motilidade total e a motilidade progressiva foram menores aos 120 minutos de incubação, quando se utilizou esse antioxidante. As diferenças de resultado podem estar relacionadas ao tipo de diluidor utilizado no experimento anteriormente citado, em virtude de conter substâncias que auxiliam na manutenção da qualidade espermática após o processo de congelação/descongelação, como, por exemplo, o porcentual elevado de gema de ovo e o OrvusEs-Past. 
Quanto ao vigor espermático (Fig. 1III), não se observou efeito dos tratamentos $(\mathrm{P}>0,05)$, embora aos 120 minutos de incubação tenha sido verificada redução dos valores médios dessa variável em T1 (sêmen + Tris) e T3 (sêmen + Tris + pentoxifilina). Por outro lado, as amostras submetidas aos T2 (sêmen + Tris + trolox) ou T4 (sêmen + Tri + pentoxifilina + trolox), após o

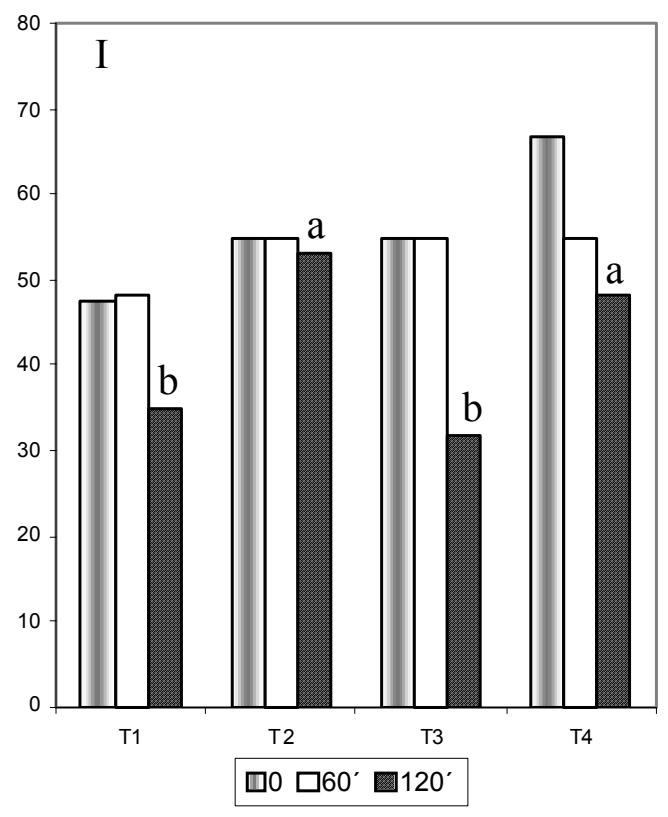

descongelamento, apresentaram valores similares $(\mathrm{P}>0,05)$ de vigor espermático, aos 120 minutos de incubação, ressaltando o efeito da vitamina $\mathrm{E}$, como uma das mais importantes moléculas antioxidantes (Ehrenkranz, 1980; Palamanda e Kehrer, 1993). Ressalta-se, ainda, não ter havido interação tratamento $\mathrm{x}$ tempo para as variáveis estudadas.

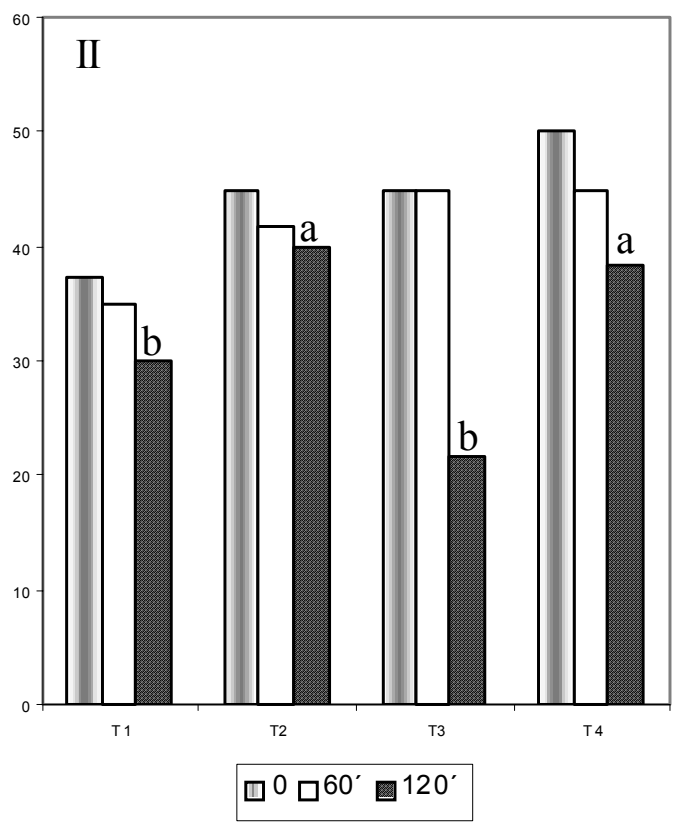

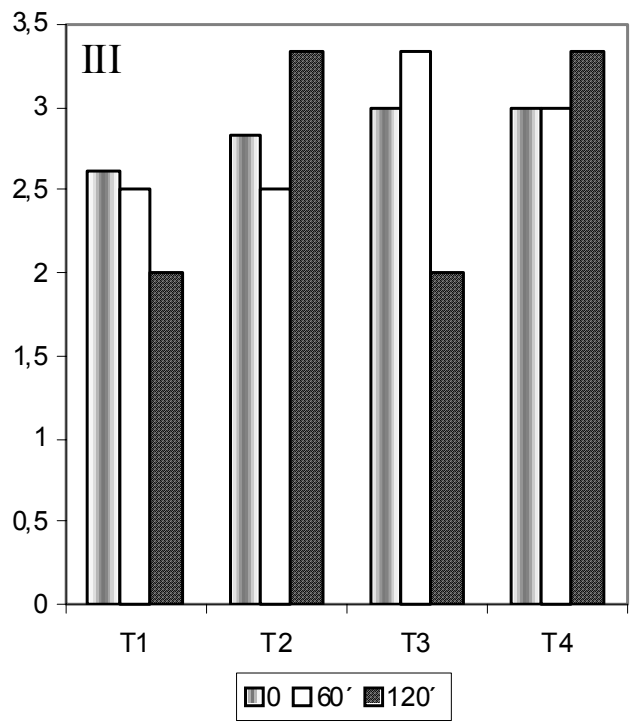

Figura 1. Porcentuais de motilidade total (I), progressiva (II) e vigor (III) de espermatozoides de equinos após descongelação e diluição em Tris (T1), acrescido de trolox (T2) ou de pentoxifilina (T3) ou de trolox + pentoxifilina (T4) após 0, 60 e 120 minutos de incubação a $37^{\circ} \mathrm{C}$. Letras distintas indicam diferença entre tratamentos $(\mathrm{P}<0,05)$. 
Observou-se redução significativa $(\mathrm{P}<0,01)$ nos porcentuais de células com acrossomas íntegros em decorrência do tempo de incubação, sendo mais acentuada aos 120 minutos no T3, 90,0\%; $89,0 \% ; 78,0 \%$; e em menor intensidade no $\mathrm{T} 4$, $93,0 \% ; 87,5 \% ; 87,0 \%$, respectivamente, aos 0 , 60 e 120 minutos de incubação (Fig. 2I). A peroxidação lipídica é iniciada pelo radical hidroxil que reage com o ácido graxo poliinsaturado, gerando radicais orgânicos livres que, em contrapartida, reagem rapidamente com o oxigênio para formar o peróxido de hidrogênio. Esses peróxidos lipídicos, que agem como radicais livres, iniciam uma reação em cadeia autocatalítica, resultando em danos à membrana celular (Cotran et al., 1989). A peroxidação lipídica e o subsequente dano de membrana ocorrem principalmente durante o processo de descongelação (Sinha et al., 1996). O estudo da integridade acrossômica evidenciou porcentuais elevados de células íntegras no decorrer dos intervalos estudados, demonstrando que nesse experimento todos os tratamentos proporcionaram ambiente adequado à integridade das membranas plasmática e acrossômica externa, evitando dano celular e preservando as células espermáticas da capacitação e da reação do acrossoma precoces, comumente observadas durante o processo de congelação (Neild et al., 2003). Este resultado difere dos relatados por Marques et al. (2000) em que o acrossoma comumente sofre alteração estrutural determinada por elevada concentração de ROS.
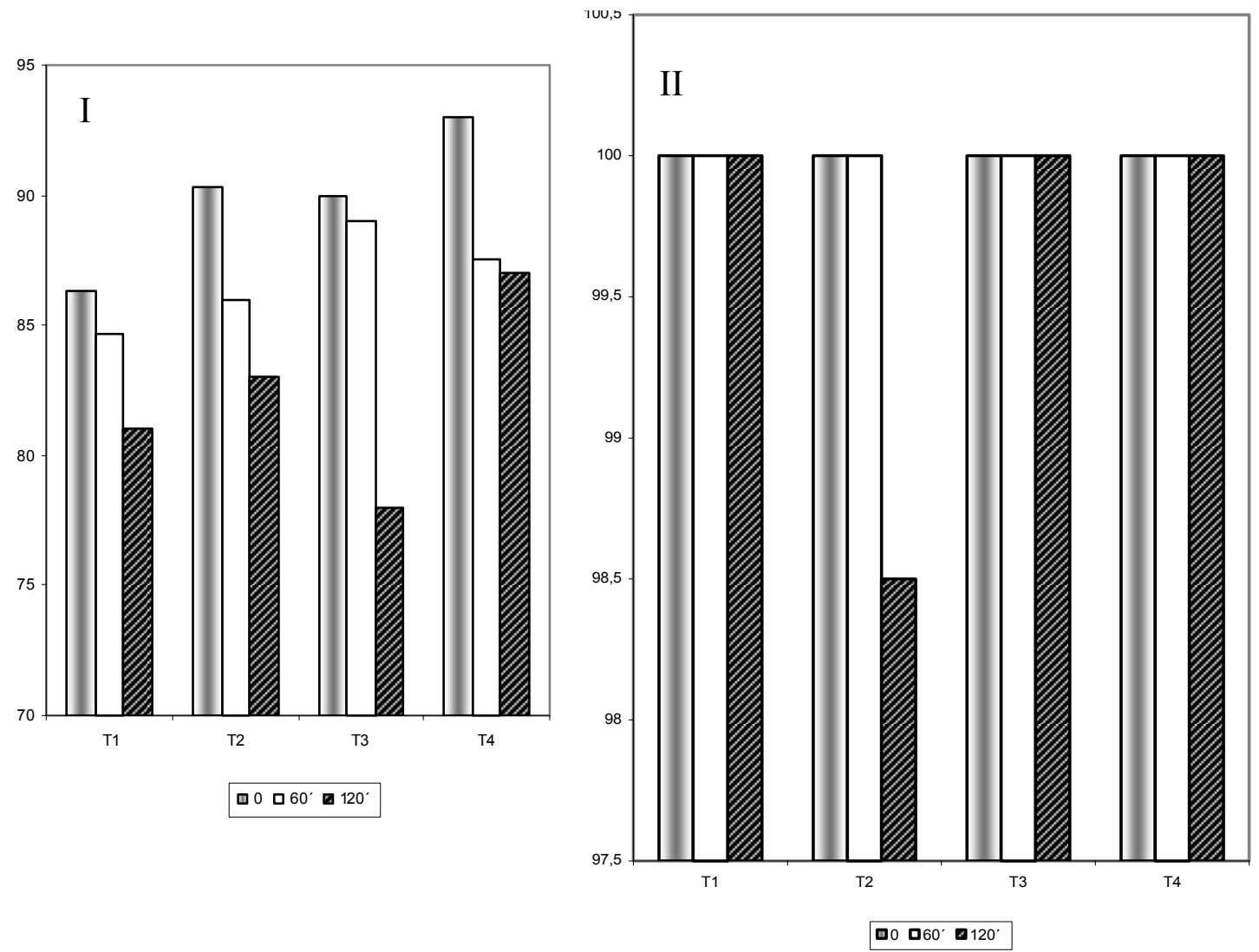

Figura 2. Porcentual de espermatozoides de equinos com acrossomas (I) e DNA (II) íntegros após descongelação e diluição em Tris (T1), acrescido de trolox (T2) ou de pentoxifilina (T3) ou de trolox + pentoxifilina (T4) após 0,60 e 120 minutos de incubação a $37^{\circ} \mathrm{C}$. 
No T3, após 120 minutos de incubação, observou-se redução acentuada dos valores de todos os parâmetros observados, com exceção da análise do DNA que manteve $100,0 \%$ das células íntegras. Baixa qualidade da cromatina detectada em espermatozoides morfologicamente anormais pode representar um dos maiores fatores limitantes da habilidade fertilizante do espermatozoide, dando ênfase à importância da integridade do DNA como expressão do potencial de fertilidade (Frase, 2004). Todavia, neste experimento, a análise de integridade do DNA espermático não evidenciou diferença $(\mathrm{P}<0,05)$ entre os tratamentos e os tempos de incubação, demonstrando que o processo de congelação não danificou o material genético encontrado no núcleo desses gametas. Esse fato evidencia que, quando as células espermáticas encontram-se em condições favoráveis à manutenção da integridade do DNA, não é necessária a adição de substâncias antioxidantes como trolox e pentoxifilina após a descongelação, confirmando os resultados obtidos por Donelly et al. (1999), em amostras contendo espermatozoides com mais de $80 \%$ de integridade de DNA. Esses autores verificaram que a adição de antioxidantes como ascorbato ou $\alpha$-tocoferol não determinou efeito positivo na qualidade espermática, apesar de esses antioxidantes promoverem decréscimo na produção de ROS.

A manutenção da estrutura do DNA imediatamente após a descongelação $(0 \mathrm{~min})$ e durante a incubação a $37^{\circ} \mathrm{C}(120 \mathrm{~min})$ pode ser atribuída ao fato de o grau de compactação da cromatina espermática proporcionar proteção e manutenção de sua integridade, tornando os espermatozoides mais resistentes às mutações e ao estresse ambiental (Perreault et al., 1988). Isto confirma os resultados observados por Peris et al. (2004) que, após descongelar espermatozoides ovinos e incubá-los por três horas a $38^{\circ} \mathrm{C}$, não detectaram danos ao DNA genômico.

Nas variáveis motilidade total e progressiva, aos 120 minutos de incubação, a associação de trolox e pentoxifilina (T4) conferiu valores mais elevados $(\mathrm{P}<0,05)$ do que aqueles obtidos com a adição de pentoxifilina (T3), porém os valores foram semelhantes àqueles constatados com 0 uso do trolox (T2). Esperava-se que a associação dos dois antioxidantes (trolox e pentoxifilina) apresentasse efeito potencializante, conferindo maior proteção às células espermáticas contra a ação de ROS, uma vez que, em experimento com sêmen refrigerado de equino, a pentoxifilina reduziu os efeitos deletérios dos radicais livres de oxigênio sobre a atividade celular (Goulart et al., 2004). No entanto, neste experimento, as evidências indicam que os resultados obtidos no tratamento T4 devem ser atribuídos apenas à ação do trolox, independente da adição de pentoxifilina.

Assim, pode-se concluir que a adição de $120 \mu \mathrm{M} / \mathrm{mL}$ de trolox ao diluente utilizado após a descongelação do sêmen equino preserva a motilidade total e progressiva das células espermáticas submetidas à incubação a $37^{\circ} \mathrm{C}$ durante 120 minutos.

\section{AGRADECIMENTOS}

Ao $\mathrm{CNPq}$, pelo apoio financeiro, e à médica veterinária Ana Emília Motta (Haras Aparthorse - Camaragibe/PE), pela concessão dos garanhões utilizados nesse estudo.

\section{REFERÊNCIAS BIBLIOGRÁFICAS}

BALL, B.A.; VO, A.T.; BAUMBER, J. Generation of rective oxygen species by equine spermatozoa. Am . J. Vet. Res., v.62, p.508-515, 2001.

BILODEAU, J.F.; BLANCHETTE, S.; GAGNON, C. et al. Levels of antioxidants defences are decreased in bovine spermatozoa after a cycle of freezing and thawing. Mol. Reprod. Dev., v.55, p.282-288, 2000.

CHATTERJEE, S.; GAGNON, C. Production of reactive oxygen species by spermatozoa undergoing cooling, freezing, and thawing. Mol. Reprod. Dev., v.59, p.451-458, 2001.

COTRAN, R.S.; KUMAR, V.; ROBBINS, S.L. Pathologic basis of diseases. 4.ed. Philadelphia: W.B. Saunders, 1989. 1519p.

DELL'AQUA JÚNIOR, J.A.; PAPA, F.O. Efeito de diluentes e tempo de centrifugação, sobre os parâmetros espermáticos para congelação de sêmen equino. Rev. Bras. Reprod. Anim., v.25, p.460-462, 2001.

DIEBER-ROTHENEDER, M.; PUHL, H.; WAEG, G. et al. Effect of oral supplementation with $d-\alpha$-tocopherol on the vitamin $E$ content of 
human low density lipoproteins and resistance to oxidation. J. Lipid Res., v.32, p.1325-1332, 1991.

DONNELLY, E.T.; McCLURE, N.; LEWIS, S.E.M. The effect of ascorbate and $\alpha$-tocoferol supplementation in vitro on DNA integrity and hydrogen peroxide-induced DNA damage in human spermatozoa. Mutagenesis, v.14, p.501511,1999

EHRENKRANZ, R. Vitamin E and the neonate. Am. J. Dis. Child., v.134, p.1157-1168, 1980.

EVENSON, D.P.; JOST, L.K.; MARSHALL, D. et al. Utility of the sperm chromatin structure as a diagnostic and prognostic tool in the human fertility clinic. Hum. Reprod., v.14, p.1039-1049, 1999.

FRASE, L. Structural damage to nuclear DNA in mammalian spermatozoa: its evaluation techniques and relationship with male infertility. Polish J. Vet. Sci., v.7, p.311-321, 2004.

GADEA, J.; GUMBAO, D.; MATÁS, C. et al. Supplementation of the thawing media with reduced glutathione improves function and the in vitro fertilizing ability of boar spermatozoa after cryopreservation. J. Androl., v.26, p.749-756, 2005.

GOULART, H.M.; SILVA, A.E.D.F.; McMANUS, C. et al. Efeitos da pentoxifilina sobre a viabilidade in vitro dos espermatozoides de equinos, após o resfriamento a $5^{\circ} \mathrm{C}$, Rev. Bras. Zootec., v.33, p.112-122, 2004.

GUERRA, M.M.P.; EVANS, G.; MAXWELL, W.M.C. Papel de oxidantes e anti-oxidantes na andrologia (revisão de literatura). Rev. Bras. Reprod. Anim., v.28, p.189-196, 2004.

HALLIWELL, B.; GUTTERIDGE, J.M.C. Free radicals in biology and medicine. 3.ed. Oxford: Clarendon and Oxford University, 1999. 936p.

JONES, D.P.; KAGAN, V.E.; AUST, S.D. et al. Impact of nutrients on cellular lipid peroxidation and antioxidant defence system. Fundam. Appl. Toxicol., v.26, p.1-7, 1995.

KAGAN, V.E.; SERBINOVA, E.A.; FORTE, T. et al. Recycling of vitamin $\mathrm{E}$ in low density lipoproteins. J. Lipid. Res., v.33, p.385-397, 1992.

KENNEY, R.M.; BERMAN, R.V; COOPER, W.L et al. Minimal contamination techniques for breeding mares: technique and preliminary findings. In: ANNUAL CONVENTION AMERICAN ASSOCIATION EQUINE PRACTIONERS, 21., 1975, Boston. Proceedings... Boston, AAEP, 1975. p.327-336.

MANUAL para exame andrológico e avaliação de sêmen animal. 2.ed. Belo Horizonte: CBRA, 1998. 49p.

MARQUES, A.; ARRUDA, R.P.; CELEGHINI, E.C.C. et al. Effects of ascobic acid and pentoxifylline on equine cryopreserved semen submitted to in vitro incubation. Theriogenology, v.58, p.257-260, 2002.

MICKLE, D.A.; LI, R.K.; WEISEL, R.D. et al. Miocardial salvage with trolox and ascorbic acid for an acute envolving infarction. Ann. Thorac. Surg., v.47, p.203-213, 1997.

NEILD, D.M.; GADELLA, B.M.; CHAVES, M.G. et al. Membrane changes during different stages of a freeze-thaw protocol for equine semen cryopreservation. Theriogenology, v.59, p.1693-1705, 2003.

PALAMANDA, J.R.; KEHRER, J.P. Involvement of vitamin $\mathrm{E}$ and protein thiols in the inhibition of microssomal lipid peroxidation by glutathione. Lipids, v.28, p.427-431, 1993.

PERIS, S.I.; MORRIER, A.; DUFOUR, M. et al. Cryopreservation of ram semen facilitates sperm DNA damage: relationship between sperm andrological parameters and the sperm chromatin structure assay. J. Androl., v.25, p.224-233, 2004.

PERREAULT, S.D.; BARBEE, R.R.; SLOTT, V.L. Importance of glutathione in the acquisition and maintenance of sperm nuclear decondensing activity in maturing hamster oocytes. Dev. Biol., v.125, p.181-186, 1988.

ROTH, T.L.; WEISS, R.B.; BUFF, L.M. et al. Heterologous in vitro fertilization and sperm capacitation in an endangered African antelope, the Scimiltar-Horned Oryx (Oryx dammah). Biol. Reprod., v.58, p.475-482, 1998.

SIKKA, S.C. Role of oxidative stress and antioxidants in andrology and assisted reproductive technology. J. Androl., v.25, p.5-18, 2004.

SILVA, E.C.B.; SILVA, K.M.G.; MORAES, T.A.P. et al. Eficiência de trolox e pentoxifilina na diluição, pós-descongelação, de amostras de 
sêmen de garanhões da raça Mangalarga Marchador. In: CONGRESSO NORTENORDESTE DE REPRODUÇÃO ANIMAL, 3., 2006, Belém. Anais... Belém: CBRA/Regional Norte-Nordeste, 2006. CD-ROM. (Resumo).

SINHA, M.P.; SINHA, A.K.; SINGH, B.K. et al. The effect of glutathiona on the motility, enzyme leakage and fertility of frozen goat semen. Anim. Reprod. Sci., v.41, p.237-243, 1996.

SNOECK, P.P.N.; HENRY, M.; MELO, M.I.V. Efeito de diferentes diluidores sobre a viabilidade espermática pós-descongelação de sêmen equino. Arq. Bras. Med. Vet. Zootec., v.59, p.56-64, 2007.

YOVICH, J.L. Pentoxifylline: actions and applications in assisted reproduction. Hum. Reprod., v.8, p.1786-1791, 1993.
TWIGG, J.; IRWINE, D.S.; HOUSTON, P. et al. Iatrogenic DNA damage induced in human spermatozoa during sperm preparation: protective significance of seminal plasma. Mol. Hum. Reprod., v.4, p.439-445, 1998.

WANG, A.W.; ZHANG, H.; IKEMOTO, I. et al. Reactive oxygen species generation by seminal cells during cryopreservation. Urology, v.49, p.921-925, 1997.

WU, T.W.; HASHIMOTO, N.; WU, J. et al. The cryoprotective effect of trolox demonstrated with three types of human cells. Biochem. Cell Biol., v.68, p.1189, 1990.

WU, T.W.; HASHIMOTO, N.; AU, J.X. et al. Trolox protects rat hepatocytes against oxyradical damage and the ischemic rat liver from reperfusion injury. Hepatology, v.13, p.575-580, 1991. 